\title{
Uusioersily
}

\section{Antibacterial and antioxidant potential of biosynthesized copper nanoparticles mediated through Cissus arnotiana plant extract}

Tambuwala, M. M. (2019). Antibacterial and antioxidant potential of biosynthesized copper nanoparticles mediated through Cissus arnotiana plant extract. JOURNAL OF PHOTOCHEMISTRY AND PHOTOBIOLOGY B-BIOLOGY, 197, [111531]. https://doi.org/10.1016/j.jphotobiol.2019.111531, https://doi.org/10.1016/j.jphotobiol.2019.111531

Link to publication record in Ulster University Research Portal

Published in:

JOURNAL OF PHOTOCHEMISTRY AND PHOTOBIOLOGY B-BIOLOGY

Publication Status:

Published (in print/issue): 31/08/2019

DOI:

10.1016/j.jphotobiol.2019.111531

https://doi.org/10.1016/j.jphotobiol.2019.111531

\section{Document Version}

Author Accepted version

\section{General rights}

Copyright for the publications made accessible via Ulster University's Research Portal is retained by the author(s) and / or other copyright owners and it is a condition of accessing these publications that users recognise and abide by the legal requirements associated with these rights.

\section{Take down policy}

The Research Portal is Ulster University's institutional repository that provides access to Ulster's research outputs. Every effort has been made to ensure that content in the Research Portal does not infringe any person's rights, or applicable UK laws. If you discover content in the Research Portal that you believe breaches copyright or violates any law, please contact pure-support@ulster.ac.uk. 


\section{Accepted Manuscript}

Photochemistry

Antibacterial and antioxidant potential of biosynthesized copper nanoparticles mediated through Cissus arnotiana plant extract

S. Rajeshkumar, Soumya Menon, S. Venkat Kumar, Murtaza M. Tambuwala, Hamid A. Bakshi, Meenu Mehta, Saurabh Satija, Gaurav Gupta, Dinesh Kumar Chellappan, T. Lakshmi, Kamal

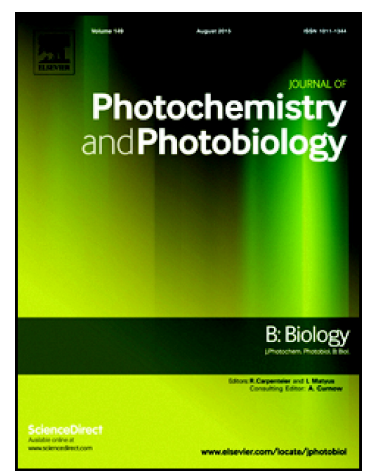

Dua

PII:

S1011-1344(19)30521-4

DOI: https://doi.org/10.1016/j.jphotobiol.2019.111531

Article Number: 111531

Reference: JPB 111531

To appear in: Journal of Photochemistry \& Photobiology, B: Biology

Received date: 29 April 2019

Revised date: 29 May 2019

Accepted date: 5 June 2019

Please cite this article as: S. Rajeshkumar, S. Menon, S. Venkat Kumar, et al., Antibacterial and antioxidant potential of biosynthesized copper nanoparticles mediated through Cissus arnotiana plant extract, Journal of Photochemistry \& Photobiology, B: Biology, https://doi.org/10.1016/j.jphotobiol.2019.111531

This is a PDF file of an unedited manuscript that has been accepted for publication. As a service to our customers we are providing this early version of the manuscript. The manuscript will undergo copyediting, typesetting, and review of the resulting proof before it is published in its final form. Please note that during the production process errors may be discovered which could affect the content, and all legal disclaimers that apply to the journal pertain. 


\section{Antibacterial and antioxidant potential of biosynthesized copper nanoparticles mediated through Cissus arnotiana plant extract}

Rajeshkumar $S^{1 *}$, Soumya Menon ${ }^{2}$, Venkat Kumar $S^{2}$, Murtaza M. Tambuwala ${ }^{3}$, Hamid A. Bakshi $^{3}$, Meenu Mehta ${ }^{4}$, Saurabh Satija ${ }^{4}$, Gaurav Gupta ${ }^{5}$, Dinesh Kumar Chellappan ${ }^{6}$, Lakshmi $\mathrm{T}^{\mathbf{1}}$, Kamal Dua ${ }^{7,8 *}$

${ }^{1}$ Department of Pharmacology, Saveetha Dental College and Hospitals, SIMATS, Chennai 600077, TN, India

${ }^{2}$ School of Bio-Sciences and Technology, Vellore Institute of Technology (VIT), Vellore 632014, TN, India

${ }^{3}$ School of Pharmacy and Pharmaceutical Sciences, Ulster University, Coleraine, County Londonderry, BT52 1SA, Northern Ireland, United Kingdom

${ }^{4}$ School of Pharmaceutical Sciences, Lovely Professional University, Jalandhar-Delhi G.T. Road (NH-1), Phagwara-144411, Punjab, India

${ }^{5}$ School of Pharmacy, Suresh Gyan Vihar University, Mahal Road, Jagatpura, Jaipur, India.

${ }^{6}$ Department of Life Sciences, School of Pharmacy, International Medical University, Bukit Jalil 57000, Kuala Lumpur, Malaysia

${ }^{7}$ Discipline of Pharmacy, Graduate School of Health, University of Technology Sydney, Sydney, NSW 2007, Australia

${ }^{8}$ School of Biomedical Sciences \& Pharmacy, University of Newcastle, Newcastle, NSW 2308, Australia

\section{*Correspondance to}

1. Dr. S. Rajeshkumar. Email id: ssrajeshkumar01@outlook.com

2. Dr. Kamal Dua. Email id: kamalpharmacist02@gmail.com 


\section{Abstract}

Environment friendly methods for the synthesis of copper nanoparticles have become a valuable trend in the current scenario. The utilization of phytochemicals from plant extracts has become a unique technology for the synthesis of nanoparticles, as they possess dual nature of reducing and capping agents to the nanoparticles. In the present investigation we have synthesized copper nanoparticles (CuNPs) using a rare medicinal plant Cissus arnotiana and evaluated their antibacterial activity against gram negative and gram positive bacteria. The morphology and characterization of the synthesized CuNPs were studied and done using UV-Visible spectroscopy at a wavelength range of 350-380nm. XRD studies were performed for analyzing the crystalline nature; SEM and TEM for evaluating the spherical shape within the size range of $60-90 \mathrm{~nm}$ and AFM was performed to check the surface roughness. The biosynthesized CuNPs showed better antibacterial activity against the gram-negative bacteria, E. coli with an inhibition zone of $22.20 \pm 0.16 \mathrm{~mm}$ at $75 \mu \mathrm{g} / \mathrm{ml}$. The antioxidant property observed was comparatively equal with the standard antioxidant agent ascorbic acid at a maximum concentration of $40 \mu \mathrm{g} / \mathrm{ml}$. This is the first study reported on C. arnotiana mediated biosynthesis of copper nanoparticles, where we believe that the findings can pave way for a new direction in the field of nanotechnology and nanomedicine where there is a significant potential for antibacterial and antioxidant activities. We predict that, these could lead to an exponential increase in the field of biomedical applications, with the utilization of green synthesized CuNPs, due to its remarkable properties. The highest antibacterial property was observed with gram-negative strains mainly, E. coli, due to its thin peptidoglycan layer and electrostatic interactions between the bacterial cell wall and CuNPs surfaces. Hence, CuNPs can be potent therapeutic agents in several biomedical applications, which are yet to be explored in the near future.

Keywords: Copper nanoparticles; DPPH Assay; Antibacterial activity; Morphology evaluation; peptidoglycan layer; electrostatic interactions; therapeutic applications

\section{Introduction}

Copper is a chemical substance with the nuclear number 29. It is a soft, mouldable and bendable substance in nature, which also has high thermal and electrical conductivities [1]. Among the different transition metals under examination, copper nanoparticles are more affordable when contrasted with similar other metals, for example; platinum, silver and gold 
[2]. CuNPs have significant physical and chemical properties [3], optical, catalytic [4], heat transfer [5], magnetic properties [6], high surface area to volume ratio [7] and also biocidal [8] properties. Due to these properties, they are utilized step by step as part of different applications, for example, in gas sensors, catalysis, thermal vitality, batteries and heat transfer fluids to name a few [9-13]. A number of methods are currently being used to prepare CuNPs, which also include sonochemical reduction, thermal reduction, capping agent method, induced radiation, vapour deposition method, laser irradiation and microemulsion techniques [14-19]. But, these methods come with few drawbacks, namely, incurring high maintenance towards the equipments, transferring hazardous chemicals to the environment and also the low availability of resources [20].

Currently, green fabrication of synthetic compounds or materials plays a key part in the betterment of humanity and for the sustainment of nature. 'Green Chemistry' is believed to be a better alternative for the production of non-toxic nanomaterials in contrast to perilous chemical compounds [21-23]. In this perspective, a new approach is developed for the synthesis of CuNPs that are mediated through Cissus arnotiana plant extract, without the utilization of any toxic chemicals or reagents.

At low concentrations, copper act as a co-factor for enzymes and metalloproteins. However, at higher concentrations, it causes hazardous effects on microbes and inhibits the bacterial growth effectively. It has been reported that copper enables the substitution of essential ions, the blockage of functional groups of proteins, generation of hydroperoxide free radicals, inactivation of crucial enzymes and modification of membrane integrity [24, 25], thereby working efficiently against microbes.

The focus of current antimicrobial research primarily revolves around developing antimicrobial agents that are cost-effective, focussing on economic healthcare strategies with less burden, and developing stronger antibiotics that are effective against several resistant microbes [26]. The demand in the utilization of natural disinfectants has led scientists to exploit the use of antimicrobial agents like iodine, copper or silver. Among these, copper has seen a significant rise in the usage as an antimicrobial agent. It is further reported that when surfaces contained no less than 55\%-70\% of copper, it resulted in destroying numerous pathogenic microorganisms. In 2008, the US Environmental Protection Agency (EPA) enlisted about 300 copper containing amalgams as antimicrobial operators that battle effectively against the multiplication of microscopic organisms responsible of dangerous contaminations. Previous reports have suggested that the mechanism behind the antibacterial 
activity of copper is due to accumulation of CuNPs, which damage the cell membrane, cytoplasm components, and intracellular enzymes, thereby releasing proteins and ions from the bacterial cells thus, inhibiting its growth [27].

In the present study, CuNPs were synthesized using Cissus arnotiana leaf extract; an effortless single step process, without the usage of toxic chemicals or reagents. The biosynthesized CuNPs were then subjected to test the antimicrobial activity against $E$. coli, Streptococcus sp., Rhizobium sp. and Klebsiella sp., while the antioxidant property was compared with standard ascorbic acid, by calculating the degree of free radical scavenging activity.

\section{Materials and methods}

Copper sulphate, DPPH and ascorbic acid were purchased from Sigma Aldrich, India. The plant samples were collected from VIT, Vellore campus garden. The bacterial cultures Escherichia coli (MTCC 1687), Streptococcus sp. (MTCC 389), Rhizobium sp. (MTCC 616) and Klebsiella sp. (MTCC 4030) were collected from MTCC India.

\subsection{Preparation of plant extract}

Fresh leaves were collected from a garden and were thoroughly double washed with running water and then with Mili-Q water. They were then dried under the sun for 5 days. The dried leaves were eventually crushed and powdered. Accurately, $1 \mathrm{~g}$ of the powder was weighed and was added to $100 \mathrm{ml}$ double distilled water, which was then boiled at $70^{\circ} \mathrm{C}$ for $30 \mathrm{~min}$. This allows the phytochemicals present in the powder to get activated. The extract was collected from Whatman filter paper 1, and stored for further use at low temperature.

\subsection{Biosynthesis of CuNPs}

A measured quantity of $10 \mathrm{ml}$ of the extract was added to $90 \mathrm{ml}$ of $10 \mathrm{mM}$ of copper sulphate and an optimized ratio of 9:1 was maintained. The mixture was kept in the stirrer at room temperature (RT) for $4 \mathrm{~h}$. The pellet was collected by centrifugation at $10,000 \mathrm{rpm}$ for $5 \mathrm{~min}$ and was washed with Double distilled water, followed by ethanol, to remove all the debris and untreated contents. The pure nanoparticle powder was collected by lyophilisation and stored at RT for further use.

\subsection{Characterisation of Copper Nanoparticles}


The maximum absorbance was measured within the range of 200-600nm [28] using a UVvisible spectrophotometer (ELICO SL 210 UV-Vis spectrophotometer). The diffraction patterns were collected through X-ray diffraction [29], using a Bruker D8 diffractometer, measured at a scanning speed of $4^{\circ} \mathrm{min}^{-1}$ and a step size of $0.02^{\circ}$. The morphology of the nanoparticles was evaluated with a scanning electron microscope [30], ZEISS (EVO18) Japan $15 \mathrm{Kv}$ and a transmission electron microscope [31]. The surface roughness was observed with atomic force microscope [32].

\subsection{Antibacterial Activity of CuNPs}

Fresh bacterial cultures were prepared, in Hi-Veg broth medium, where 10ul cultures of $E$. coli, Streptococcus sp., Rhizobium sp. and Klebsiella sp. were inoculated, and incubated for 18h, in a shaker. A nutrient agar medium was prepared and $5 \mathrm{~mm}$ wells were made, with different concentrations $(25-75 \mu \mathrm{g} / \mathrm{ml})$ of CuNPs added, along with the positive control ampicillin antibiotic disks. The plates were incubated for $18 \mathrm{~h}$, at $37^{\circ} \mathrm{C}$ and the zones of inhibition were measured $[33,34]$.

\subsection{Antioxidant Activity of CuNPs}

Hydrogen donating capacity or free radical scavenging by the nanoparticles was evaluated by the DPPH measure, which depends on the reduction of the methanolic coloured radical type of the DPPH to the non-coloured solution. A measured quantity of $0.2 \mathrm{mM}$ of DPPH was added to methanol solution, with the concentration of CuNPs at a range of $20-100 \mu \mathrm{g} / \mathrm{ml}$. Ascorbic acid was used as the standard, which was employed to compare with test nanoparticles. The solution was vortexed and incubated for $30 \mathrm{~min}$ in dark conditions. The absorbances of both test and standard were analyzed at $517 \mathrm{~nm}$ after the incubation period. The antioxidant activity was calculated by the Equation (1) [35]:

$\%$ Radical scavenging activity $=\frac{\text { Absorbance of the control }- \text { Absorbance of the Test sample }}{\text { Absorbance of the control }} \times 100$

\section{...Equation (1)}

\subsection{Statistical Analysis}

All the experimental results were performed in triplicate and the results were expressed as mean \pm Standard Deviation (SD) for 4 isolates of each type of bacterium. The calculation was done using Microsoft Excel 2010 software. Origin software was used for drawing the graphs. 
Statistical significance between the groups was determined by one-way ANOVA followed by a test for trial trend. A p-value $>0.05$ was considered statistically significant.

\section{Results and Discussion}

\subsection{UV -Visible Analysis}

The biomolecules from the plant extract were responsible for the reduction of copper sulphate to elemental forms of copper nanoparticles (zero-valent ions). These phytochemicals have the capability of reducing as well as stabilizing the synthesis reaction. The copper (II) sulphate dissolved in water dissipated to give $\mathrm{Cu}^{2+}$ and $\mathrm{SO}_{4}$. The $\mathrm{Cu}^{2+}$ further dissociates to give $\mathrm{Cu}^{0}$ by reduction action [36] by phytochemicals present in the Cissus arnotiana plant, which further aggregates to form nanoparticles from copper nuclei, with reaction time. The maximum absorbance is captured within a range of 350-380nm. As shown in the Fig.1; at the $3^{\text {rd }}$ hour, the maximum absorbance was at 1.1 , which dramatically decreased to 0.5 at the $4^{\text {th }}$ hour. This proves the agglomeration of the nanoparticles between the $3^{\text {rd }}$ and $4^{\text {th }}$ hour, which indicates the conclusion of the reaction. The centrifugation of mixture helps in separation of untreated copper sulphate, at $5000 \mathrm{rpm}$ for $7 \mathrm{~min}$. The collected pellet was double washed with double distilled water and then with ethanol, to remove all the debris. After various washing stages, the collected pellet was lyophilized and the powder was stored at RT for further usage. SPR (Surface Plasmon Resonance) was used to assay the morphology of the synthesized nanoparticles. The change of colour confirms the formation of CuNPs, which can be detected with the maximum absorbance [37].

\subsection{Morphology of Biosynthesized CuNPs using Scanning Electron Microscopy, X- ray Diffraction, Atomic Force Microscopy and Transmission Electron Microscopy}

The Fig 2(a); shows the agglomerated CuNPs observed under SEM. The shape was irregular and spherical. The results were further confirmed with TEM, as shown in Fig 2(b). The size range was evaluated using IMAGE $\mathrm{J}$ software, where, the average size range of the CuNPs was within 60-90nm, monodispersed and spherical shaped. Similar morphology was observed for CuNPs when synthesized using Acalypha indica [38], Shewanella loihica PV-4 [39], CuNPs stabilized with L-cysteine [40] and Thymus vulgaris L. leaf extract [41]. The XRD peaks are shown in Fig. 2 (c), at '111', '200' and '220' which correspond to crystalline copper nanoparticles, that were indexed to be spherical in shape. Similar results were observed, when compared with fermented fenugreek seeds [42] and also with chitosan clotted 
surface modification on CuNPs [43]. The Scherer's formula $d=K \lambda / \beta \cos \theta$ [44]; was applied to calculate the average size of the CuNPs, which was found to be in the range of $56 \pm 8 \mathrm{~nm}$. The XRD analysis was conducted in compliance with the JCPDS (Joint Committee on Powder Diffraction Standards). This confirmed the crystalline nature of the CuNPs. The AFM data as shown in Fig. 2(d) demonstrates the surface morphology of the nanoparticles. The white spots indicate the height, while the black indicates the depth.

\subsection{Antimicrobial Activity of CuNPs}

As shown in Fig. 3; the Zone of Inhibition (ZOI) of CuNPs is demonstrated against bacterial cultures. The zone of inhibition increased with the concentration of CuNPs, therefore, at $75 \mu \mathrm{g} / \mathrm{ml}$; the ZOI was the highest at $22.20 \pm 0.16$, while the lowest ZOI for Klebsiella sp. was $13.16 \pm 0.39$ at $25 \mu \mathrm{g} / \mathrm{ml}$ as shown in Table 1. Similar results were seen, when CuNPs synthesized using glycerol-polyvinyl alcohol [45], polyurethane materials with silver and copper nanoparticles [46], copper based additives [47] and copper-resistant Bacillus cereus [48]. The activity was two-fold greater than positive control antibiotics. CuNPs are highly reactive due to the property of high surface area to volume ratio, which permits them to abundantly interact with the cell membrane, and damaging the cellular genetic materials, causing cell death. The reason for the highest interaction with E. coli might be attributed to the negative charge present on the cells surface, which causes electrostatic interactions with the positive charges of the CuNPs. The possible mechanism proposed for the antibacterial activity is either endocytosis or direct diffusion. The adhesion of the CuNPs on the bacterial surface depends clearly on surface roughness, electrostatic interactions, chemical composition and hydrophobicity.

Furthermore, the attack of oxy radicals to the outer membrane, RNA, DNA or lipids, causes oxidative stress, resulting in cell death [48]. The gram-negative strains were more sensitive against the action of CuNPs, due to the unique outer layer and single peptidoglycan layer, when compared with gram-positive strains.

\subsection{Antioxidant activity of CuNPs}

The mechanism behind the antioxidant property is attributed to the inhibition of chain reaction, decomposition of peroxides, binding of transition metal ion catalysts, radical scavenging activity and inhibition of continued hydrogen abstraction. The free radicals present are unstable which cause cellular damage due to the generation of ROS that interact with other molecules in the biochemical reactions. The properties of absorbing, neutralizing 
these free radicals or quenching singlet and triplet oxygen are few crucial factors that are responsible for the antioxidant activity [49]. The highest antioxidant activity is attributed due to the presence of various bio-reductive groups of the phytochemicals present on the surface of the CuNPs [50].

According to Fig.4 and Table 2; the radical scavenging property of the CuNPs, when compared with the standard ascorbic acid, is quite similar, the highest $\%$ of inhibition is seen at $40 \mu \mathrm{g} / \mathrm{ml}$. During the experiment the presence of CuNPs dissolved in DPPH, the colour changed from deep violet to pale yellow solution, which indicated the scavenging of free radicals is complete [51]. Similar results were seen for CuNPs synthesized using Persea americana seeds [52].

\section{Conclusion}

We have successfully biosynthesized CuNPs using C. arnotiana plant extract, which is the first ever study that has been carried out and reported. The use of toxic chemicals was limited in the synthesis process, as the phytochemicals present in the extract were substituted as reducing as well as a stabilizing agent. The characterization of the CuNPs gave knowledge about the morphology, like electron microscopy of SEM and TEM, which suggested the nanoparticles have an average size range of $60-90 \mathrm{~nm}$ with a spherical shape. The absorption peak was within the range of $350-380 \mathrm{~nm}$, while the XRD proved its crystalline nature. The AFM data provided an idea about the surface roughness, which is an important aspect for the bio-adhesion on bacterial surfaces. The characterized CuNPs were then subjected to antibacterial activity against gram negative and gram positive bacterial strains, as well as antioxidant activity, against positive control ascorbic acid. The highest antibacterial property was observed with gram-negative strains, mainly, E. coli due to its thin peptidoglycan layer and also due to the electrostatic interactions between the bacterial cell wall and CuNPs surfaces. Hence, CuNPs can be a potent therapeutic agent against many biomedical applications, which could be a potential area that can be explored in future.

\section{References}


[1] P. Aazadfar, E. Solati, D. Dorranian, Properties of Au/Copper oxide nanocomposite prepared by green laser irradiation of the mixture of individual suspensions, Optical Materials, 78 (2018) 388-395.

[2] K.R. Reddy, Green synthesis, morphological and optical studies of $\mathrm{CuO}$ nanoparticles, Journal of Molecular Structure, 1150 (2017) 553-557.

[3] D. Dutta, A. Phukan, D.K. Dutta, Nanoporous montmorillonite clay stabilized copper nanoparticles: Efficient and reusable catalyst for oxidation of alcohols, Molecular Catalysis, 451 (2018) 178-185.

[4] F.L. Guzman Borda, S.J. Ribeiro de Oliveira, L.M. Seabra Monteiro Lazaro, A.J. Kalab Leiróz, Experimental investigation of the tribological behavior of lubricants with additive containing copper nanoparticles, Tribology International, 117 (2018) 52-58.

[5] M.A. Tahir, S.Z. Bajwa, S. Mansoor, R.W. Briddon, W.S. Khan, B.E. Scheffler, I. Amin, Evaluation of carbon nanotube based copper nanoparticle composite for the efficient detection of agroviruses, Journal of hazardous materials, 346 (2018) 27-35.

[6] T. Hayat, M.I. Khan, S. Qayyum, A. Alsaedi, Entropy generation in flow with silver and copper nanoparticles, Colloids and Surfaces A: Physicochemical and Engineering Aspects, 539 (2018) 335-346.

[7] V. Levchenko, R. Reisfeld, Enhancement of fluorescence of EuEDTA chelate complex in sol-gel glasses by surface plasmons of copper nanoparticles, Optical Materials, 74 (2017) 187-190.

[8] T. Kruk, K. Szczepanowicz, J. Stefańska, R.P. Socha, P. Warszyński, Synthesis and antimicrobial activity of monodisperse copper nanoparticles, Colloids and Surfaces B: Biointerfaces, 128 (2015) 17-22.

[9] D. Solairaj, P. Rameshthangam, P. Muthukumaran, J. Wilson, Studies on electrochemical glucose sensing, antimicrobial activity and cytotoxicity of fabricated copper nanoparticle immobilized chitin nanostructure, International journal of biological macromolecules, 101 (2017) 668-679.

[10] I.M.S. Araujo, R.R. Silva, G. Pacheco, W.R. Lustri, A. Tercjak, J. Gutierrez, J.R.S. Junior, F.H.C. Azevedo, G.S. Figueredo, M.L. Vega, S.J.L. Ribeiro, H.S. Barud, Hydrothermal synthesis of bacterial cellulose-copper oxide nanocomposites and evaluation of their antimicrobial activity, Carbohydrate polymers, 179 (2018) 341-349.

[11] S. Yousef, M. Tatariants, V. Makarevičius, S.-I. Lukošiūtè, R. Bendikiene, G. Denafas, A strategy for synthesis of copper nanoparticles from recovered metal of waste printed circuit boards, Journal of Cleaner Production, 185 (2018) 653-664. 
[12] M. Sajjad, I. Ullah, M.I. Khan, J. Khan, M.Y. Khan, M.T. Qureshi, Structural and optical properties of pure and copper doped zinc oxide nanoparticles, Results in Physics, 9 (2018) 1301-1309.

[13] M. Goswami, A.M. Das, Synthesis of cellulose impregnated copper nanoparticles as an efficient heterogeneous catalyst for $\mathrm{CN}$ coupling reactions under mild conditions, Carbohydrate polymers, 195 (2018) 189-198.

[14] K. Daun, J. Menser, R. Mansmann, S.T. Moghaddam, T. Dreier, C. Schulz, Spectroscopic models for laser-heated silicon and copper nanoparticles, Journal of Quantitative Spectroscopy and Radiative Transfer, 197 (2017) 3-11.

[15] L. Zhou, S. Wang, H. Ma, S. Ma, D. Xu, Y. Guo, Size-controlled synthesis of copper nanoparticles in supercritical water, Chemical Engineering Research and Design, 98 (2015) $36-43$.

[16] A. Wong, A.M. Santos, T.A. Silva, O. Fatibello-Filho, Simultaneous determination of isoproterenol, acetaminophen, folic acid, propranolol and caffeine using a sensor platform based on carbon black, graphene oxide, copper nanoparticles and PEDOT:PSS, Talanta, 183 (2018) 329-338.

[17] W. Leng, H.M. Barnes, Q. Yan, Z. Cai, J. Zhang, Low temperature synthesis of graphene-encapsulated copper nanoparticles from kraft lignin, Materials Letters, 185 (2016) 131-134.

[18] C. Ahoba-Sam, U. Olsbye, K.-J. Jens, Low temperature methanol synthesis catalyzed by copper nanoparticles, Catalysis Today, 299 (2018) 112-119.

[19] H.N. Pazhooh, R. Bagheri, A. Adloo, Fabrication of semi-conductive natural rubber nanocomposites with low copper nanoparticle contents, Polymer, 108 (2017) 135-145.

[20] J. Zhang, Y.n. Xu, S. Chen, J. Li, W. Han, X. Sun, D. Wu, Z. Hu, L. Wang, Enhanced antifouling and antibacterial properties of poly (ether sulfone) membrane modified through blending with sulfonated poly (aryl ether sulfone) and copper nanoparticles, Applied Surface Science, 434 (2018) 806-815.

[21] A. Happy, M. Soumya, S. Venkat Kumar, S. Rajeshkumar, Mechanistic study on antibacterial action of zinc oxide nanoparticles synthesized using green route, Chemicobiological interactions, 286 (2018) 60-70.

[22] S. Rajeshkumar, L.V. Bharath, Mechanism of plant-mediated synthesis of silver nanoparticles - A review on biomolecules involved, characterisation and antibacterial activity, Chemico-biological interactions, 273 (2017) 219-227. 
[23] R. Shanmugam, M. Chelladurai, In Vitro Antibacterial Activity and Mechanism of Silver Nanoparticles against Foodborne Pathogens, 2014.

[24] N. Arjunan, C.M. Singaravelu, J. Kulanthaivel, J. Kandasamy, A potential photocatalytic, antimicrobial and anticancer activity of chitosan-copper nanocomposite, International journal of biological macromolecules, 104 (2017) 1774-1782.

[25] A.M. Al-Enizi, T. Ahamad, A.B. Al-Hajji, J. Ahmed, A.A. Chaudhary, S.M. Alshehri, Cellulose gum and copper nanoparticles based hydrogel as antimicrobial agents against urinary tract infection (UTI) pathogens, International journal of biological macromolecules, 109 (2018) 803-809.

[26] G. Gotzmann, C. Jorsch, C. Wetzel, H.W.R. Funk, Antimicrobial effects and dissolution properties of silver copper mixed layers, Surface and Coatings Technology, 336 (2018) 2228.

[27] M. Vincent, P. Hartemann, M. Engels-Deutsch, Antimicrobial applications of copper, International journal of hygiene and environmental health, 219 (2016) 585-591.

[28] D. Sharma, M.I. Sabela, S. Kanchi, K. Bisetty, A.A. Skelton, B. Honarparvar, Green synthesis, characterization and electrochemical sensing of silymarin by $\mathrm{ZnO}$ nanoparticles: Experimental and DFT studies, Journal of Electroanalytical Chemistry, 808 (2018) 160-172.

[29] P. Das, K. Kumar, A. Nambiraj, R. Rajan, R. Awasthi, K. Dua, H. M, Potential therapeutic activity of Phlogacanthus thyrsiformis Hardow (Mabb) flower extract and its biofabricated silver nanoparticles against chemically induced urolithiasis in male Wistar rats, International journal of biological macromolecules, 103 (2017) 621-629.

[30] V. Velu, M. Das, N.A. Raj, K. Dua, H. Malipeddi, Evaluation of in vitro and in vivo anti-urolithiatic activity of silver nanoparticles containing aqueous leaf extract of Tragia involucrata, Drug Deliv Transl Res, 7 (2017) 439-449.

[31] S. Rajeshkumar, S.V. Kumar, A. Ramaiah, H. Agarwal, T. Lakshmi, S.M. Roopan, Biosynthesis of zinc oxide nanoparticles usingMangifera indica leaves and evaluation of their antioxidant and cytotoxic properties in lung cancer (A549) cells, Enzyme and microbial technology, 117 (2018) 91-95.

[32] S. Rajeshkumar, Synthesis of silver nanoparticles using fresh bark of Pongamia pinnata and characterization of its antibacterial activity against gram positive and gram negative pathogens, Resource-Efficient Technologies, 2 (2016) 30-35.

[33] M. Chelladurai, R. Shanmugam, K. Paulkumar, M. Vanaja, G. Gnanajobitha, A. Gurusamy, Biosynthesis and Antimicrobial Activity of Semiconductor Nanoparticles against Oral Pathogens, 2014. 
[34] N. Pantidos, M.C. Edmundson, L. Horsfall, Room temperature bioproduction, isolation and anti-microbial properties of stable elemental copper nanoparticles, New biotechnology, 40 (2018) 275-281.

[35] S. Jain, A. Jain, P. Kachhawah, V. Devra, Synthesis and size control of copper nanoparticles and their catalytic application, Transactions of Nonferrous Metals Society of China, 25 (2015) 3995-4000.

[36] J. Suárez-Cerda, H. Espinoza-Gómez, G. Alonso-Núñez, I.A. Rivero, Y. Gochi-Ponce, L.Z. Flores-López, A green synthesis of copper nanoparticles using native cyclodextrins as stabilizing agents, Journal of Saudi Chemical Society, 21 (2017) 341-348.

[37] M.I. Nabila, K. Kannabiran, Biosynthesis, characterization and antibacterial activity of copper oxide nanoparticles (CuO NPs) from actinomycetes, Biocatalysis and Agricultural Biotechnology, 15 (2018) 56-62.

[38] R. Sivaraj, P.K. Rahman, P. Rajiv, S. Narendhran, R. Venckatesh, Biosynthesis and characterization of Acalypha indica mediated copper oxide nanoparticles and evaluation of its antimicrobial and anticancer activity, Spectrochimica acta. Part A, Molecular and biomolecular spectroscopy, 129 (2014) 255-258.

[39] Q. Lv, B. Zhang, X. Xing, Y. Zhao, R. Cai, W. Wang, Q. Gu, Biosynthesis of copper nanoparticles using Shewanella loihica PV-4 with antibacterial activity: Novel approach and mechanisms investigation, Journal of hazardous materials, 347 (2018) 141-149.

[40] N. Kumar, L.S.B. Upadhyay, Facile and green synthesis of highly stable l-cysteine functionalized copper nanoparticles, Applied Surface Science, 385 (2016) 225-233.

[41] Z. Issaabadi, M. Nasrollahzadeh, S.M. Sajadi, Green synthesis of the copper nanoparticles supported on bentonite and investigation of its catalytic activity, Journal of Cleaner Production, 142 (2017) 3584-3591.

[42] A.I. El-Batal, N.E. Al-Hazmi, F.M. Mosallam, G.S. El-Sayyad, Biogenic synthesis of copper nanoparticles by natural polysaccharides and Pleurotus ostreatus fermented fenugreek using gamma rays with antioxidant and antimicrobial potential towards some wound pathogens, Microbial pathogenesis, 118 (2018) 159-169.

[43] N. Ali, Awais, T. Kamal, M. Ul-Islam, A. Khan, S.J. Shah, A. Zada, Chitosan-coated cotton cloth supported copper nanoparticles for toxic dye reduction, International journal of biological macromolecules, 111 (2018) 832-838.

[44] K.M. Rajesh, B. Ajitha, Y.A.K. Reddy, Y. Suneetha, P.S. Reddy, Assisted green synthesis of copper nanoparticles using Syzygium aromaticum bud extract: Physical, optical and antimicrobial properties, Optik, 154 (2018) 593-600. 
[45] K. Dobrovolný, P. Ulbrich, M. Švecová, S. Rimpelová, J. Malinčík, M. Kohout, J. Svoboda, V. Bartůněk, Copper nanoparticles in glycerol-polyvinyl alcohol matrix: In situ preparation, stabilisation and antimicrobial activity, Journal of Alloys and Compounds, 697 (2017) 147-155.

[46] Y. Savelyev, A. Gonchar, B. Movchan, A. Gornostay, S. Vozianov, A. Rudenko, R. Rozhnova, T. Travinskaya, Antibacterial polyurethane materials with silver and copper nanoparticles, Materials Today: Proceedings, 4 (2017) 87-94.

[47] H. Palza, M. Nunez, R. Bastias, K. Delgado, In situ antimicrobial behavior of materials with copper-based additives in a hospital environment, International journal of antimicrobial agents, 51 (2018) 912-917.

[48] M. Tiwari, P. Jain, R. Chandrashekhar Hariharapura, K. Narayanan, U. Bhat K, N. Udupa, J.V. Rao, Biosynthesis of copper nanoparticles using copper-resistant Bacillus cereus, a soil isolate, Process Biochemistry, 51 (2016) 1348-1356.

[49] D. Rehana, D. Mahendiran, R.S. Kumar, A.K. Rahiman, Evaluation of antioxidant and anticancer activity of copper oxide nanoparticles synthesized using medicinally important plant extracts, Biomedicine $\&$ pharmacotherapy $=$ Biomedecine $\&$ pharmacotherapie, 89 (2017) 1067-1077.

[50] M.R. Nunes, M. de Souza Maguerroski Castilho, A.P. de Lima Veeck, C.G. da Rosa, C.M. Noronha, M.V.O.B. Maciel, P.M. Barreto, Antioxidant and antimicrobial methylcellulose films containing Lippia alba extract and silver nanoparticles, Carbohydrate polymers, 192 (2018) 37-43.

[51] P. Adwin Jose, J. Dhaveethu Raja, M. Sankarganesh, J. Rajesh, Evaluation of antioxidant, DNA targeting, antimicrobial and cytotoxic studies of imine capped copper and nickel nanoparticles, Journal of Photochemistry and Photobiology B: Biology, 178 (2018) 143-151.

[52] S. Rajeshkumar, G. Rinitha, Nanostructural characterization of antimicrobial and antioxidant copper nanoparticles synthesized using novel Persea americana seeds, OpenNano, 3 (2018) 18-27.

Table 1: Antibacterial activity of CuNPs containing $C$. arnotiana plant extract

\begin{tabular}{|l|l|l|l|l|}
\hline $\begin{array}{l}\text { Concentrationof } \\
\text { CuNPs }\end{array}$ & E. coli & Streptococcus sp. & Rhizobium sp. & Klebsiella sp. \\
$(\mu \mathrm{g} / \mathrm{ml})$ & & & & \\
\hline
\end{tabular}




\begin{tabular}{|l|l|l|l|l|}
\hline 25 & $16.20 \pm 0.17$ & $15.37 \pm 0.79$ & $14.27 \pm 0.24$ & $13.16 \pm 0.39$ \\
\hline 50 & $19.20 \pm 0.11$ & $20.59 \pm 0.12$ & $16.07 \pm 0.25$ & $15.20 \pm 0.12$ \\
\hline 75 & $22.20 \pm 0.16$ & $20.23 \pm 0.35$ & $16.33 \pm 0.13$ & $18.25 \pm 0.12$ \\
\hline Ampicillin & $6.00 \pm 0$ & $6.00 \pm 0$ & $6.00 \pm 0$ & $6.00 \pm 0$ \\
\hline
\end{tabular}

\pm Standard deviation, $\mathrm{p}$-value $>0.05$

Table 2: Antioxidant activity of CuNPs biosynthesized using $C$. arnotiana compared with ascorbic acid

\begin{tabular}{|l|l|l|}
\hline $\begin{array}{l}\text { Sample concentration } \\
(\boldsymbol{\mu g} / \mathbf{m l})\end{array}$ & \% radical scavenging activity \\
\hline & CuNPs & Ascorbic acid \\
\hline 20 & $18 \pm 1$ & $23 \pm 1$ \\
\hline 40 & $21 \pm 2$ & $22 \pm 4$ \\
\hline 60 & $20 \pm 8$ & $23 \pm 7$ \\
\hline 80 & $19 \pm 6$ & $22 \pm 9$ \\
\hline 100 & $18 \pm 2$ & $23 \pm 3$ \\
\hline
\end{tabular}

\pm Standard deviation, $\mathrm{p}$-value $>0.05$ 


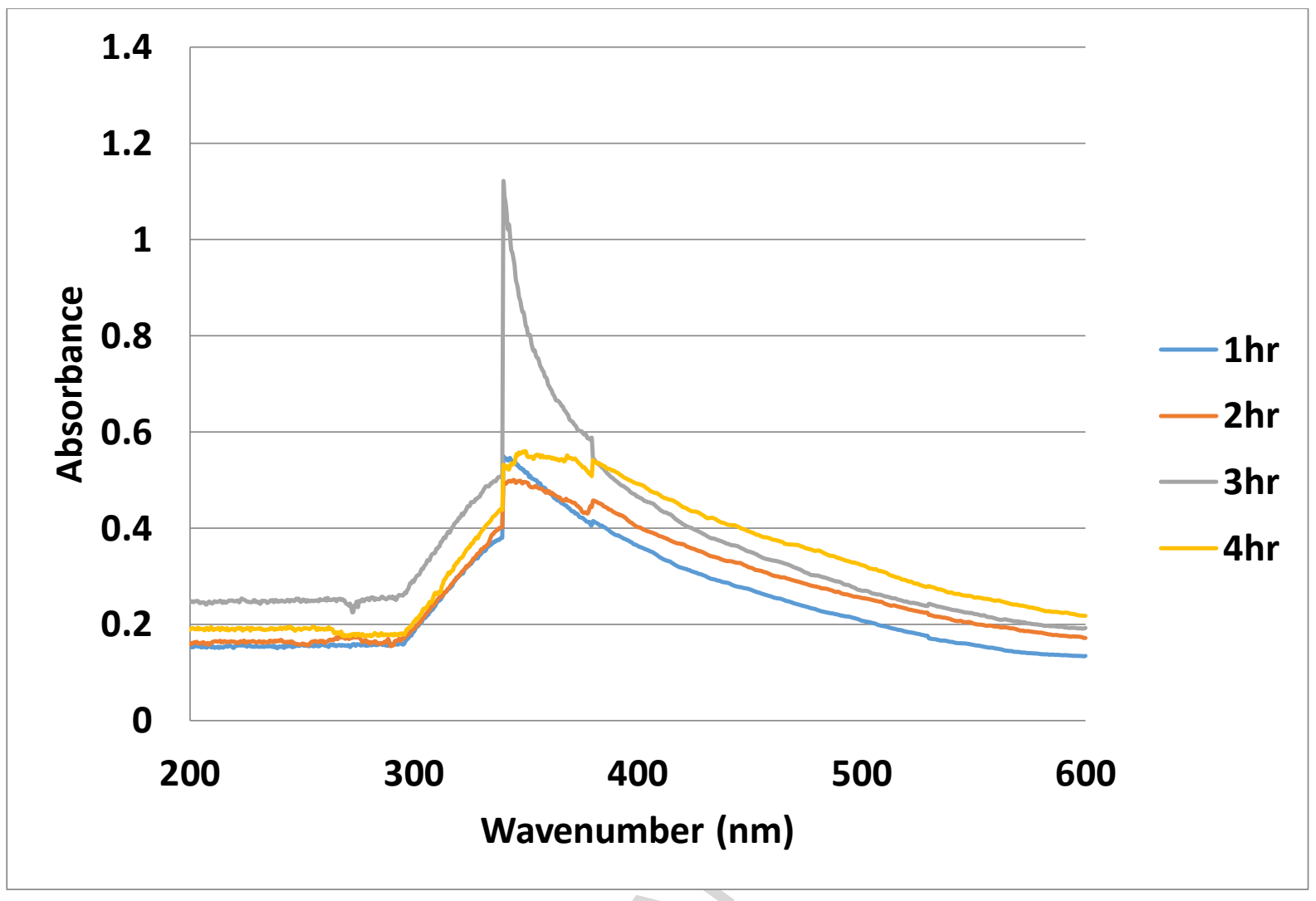

Figure 1: UV-Visible spectroscopic data for synthesized CuNPs containing Cissus arnotiana plant extract 
(a)

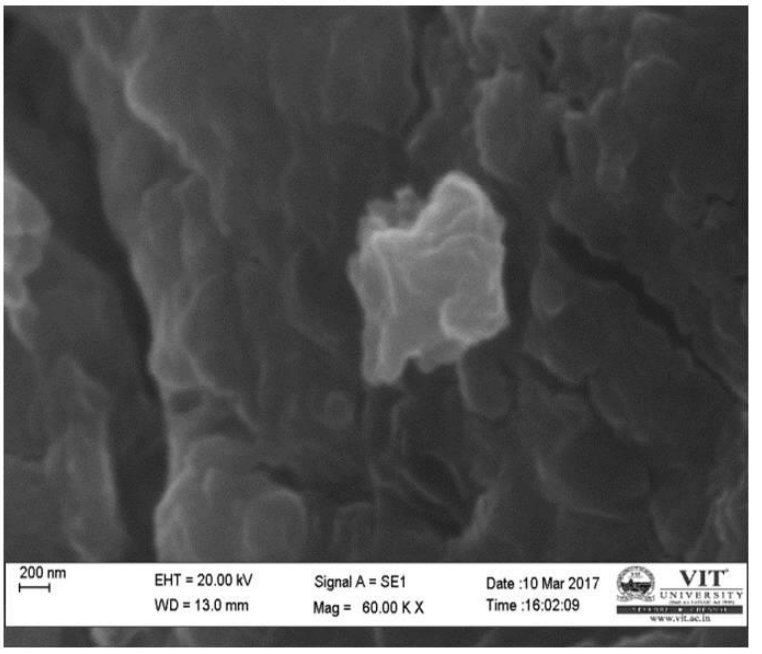

(c)

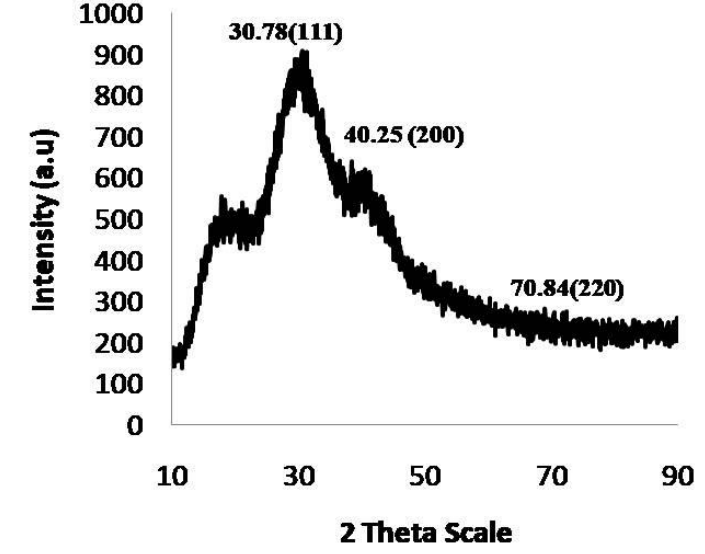

(b)

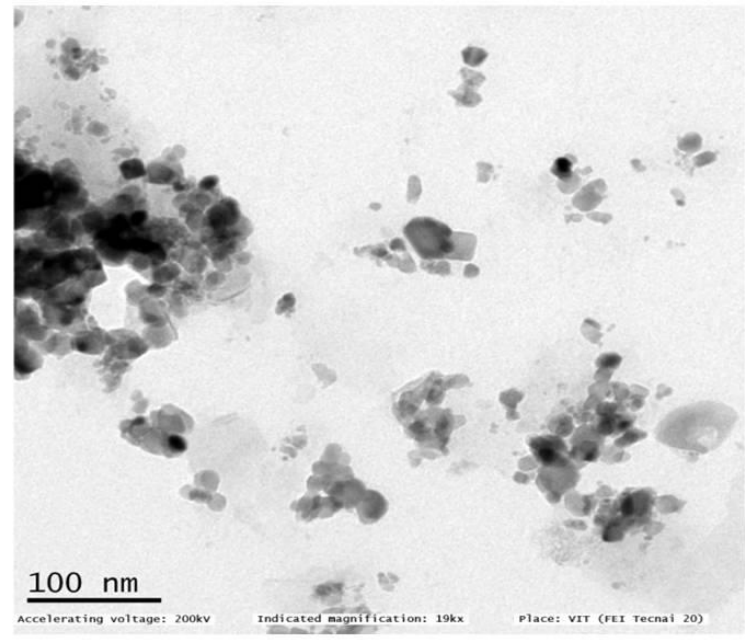

(d)

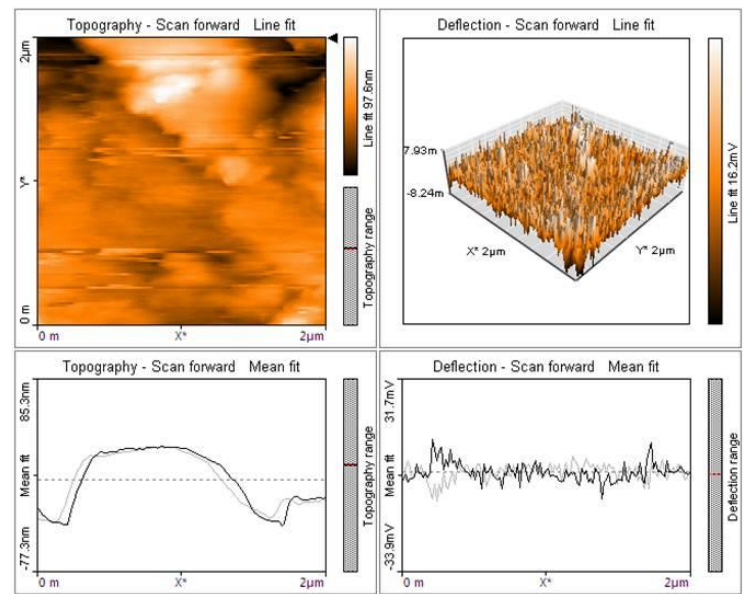

Figure 2 (a) SEM analysis (b) TEM analysis (c) XRD data and (f) AFM data analysis of CuNPs biosynthesized using $C$. arnotiana plant extract 

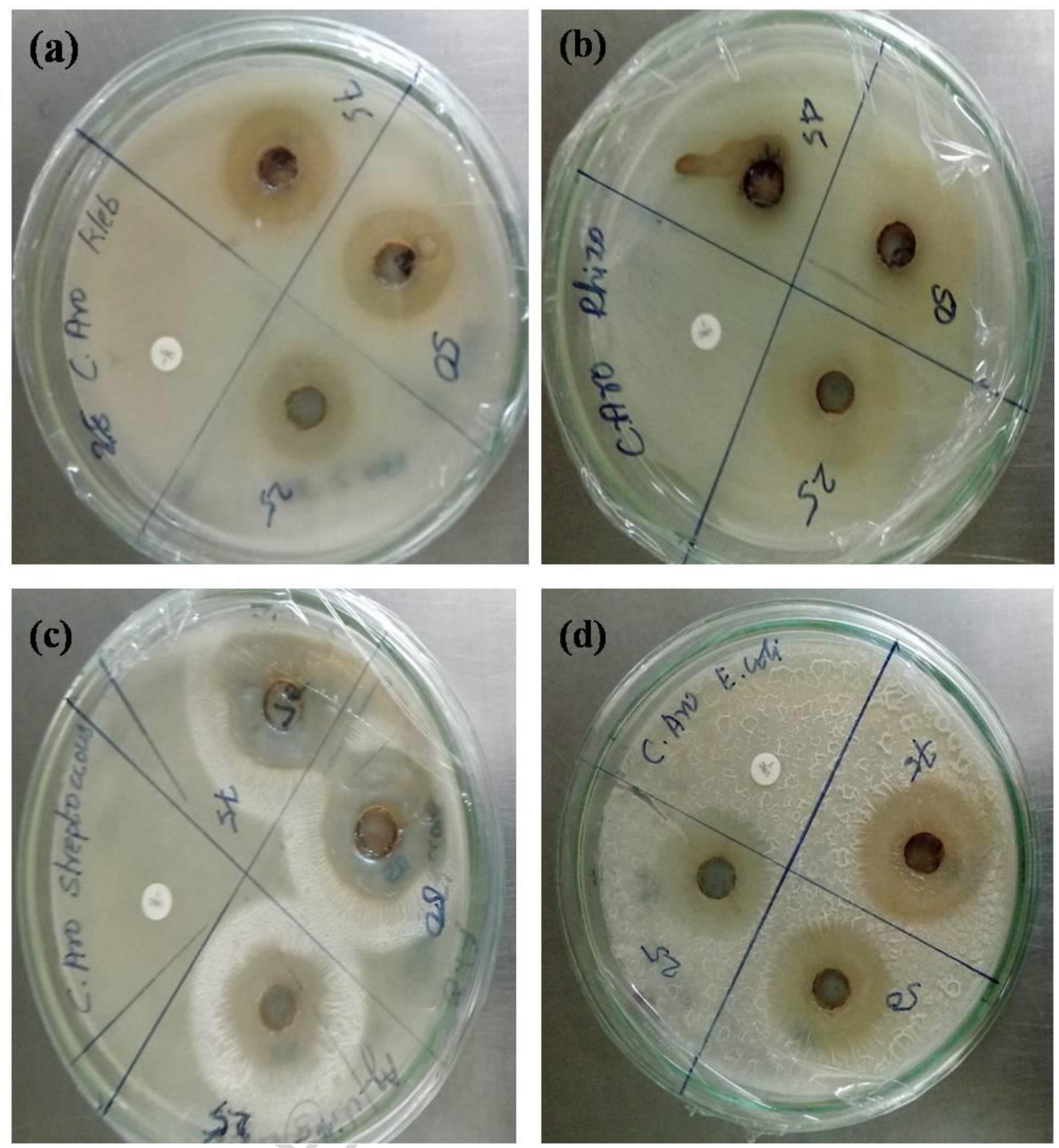

Figure 3: Zone of inhibition with CuNPs containing $C$. arnotiana plant extract against (a) Klebsiella sp. (b) Rhizobium sp. (c) Streptococcus sp. and (d) E.coli 


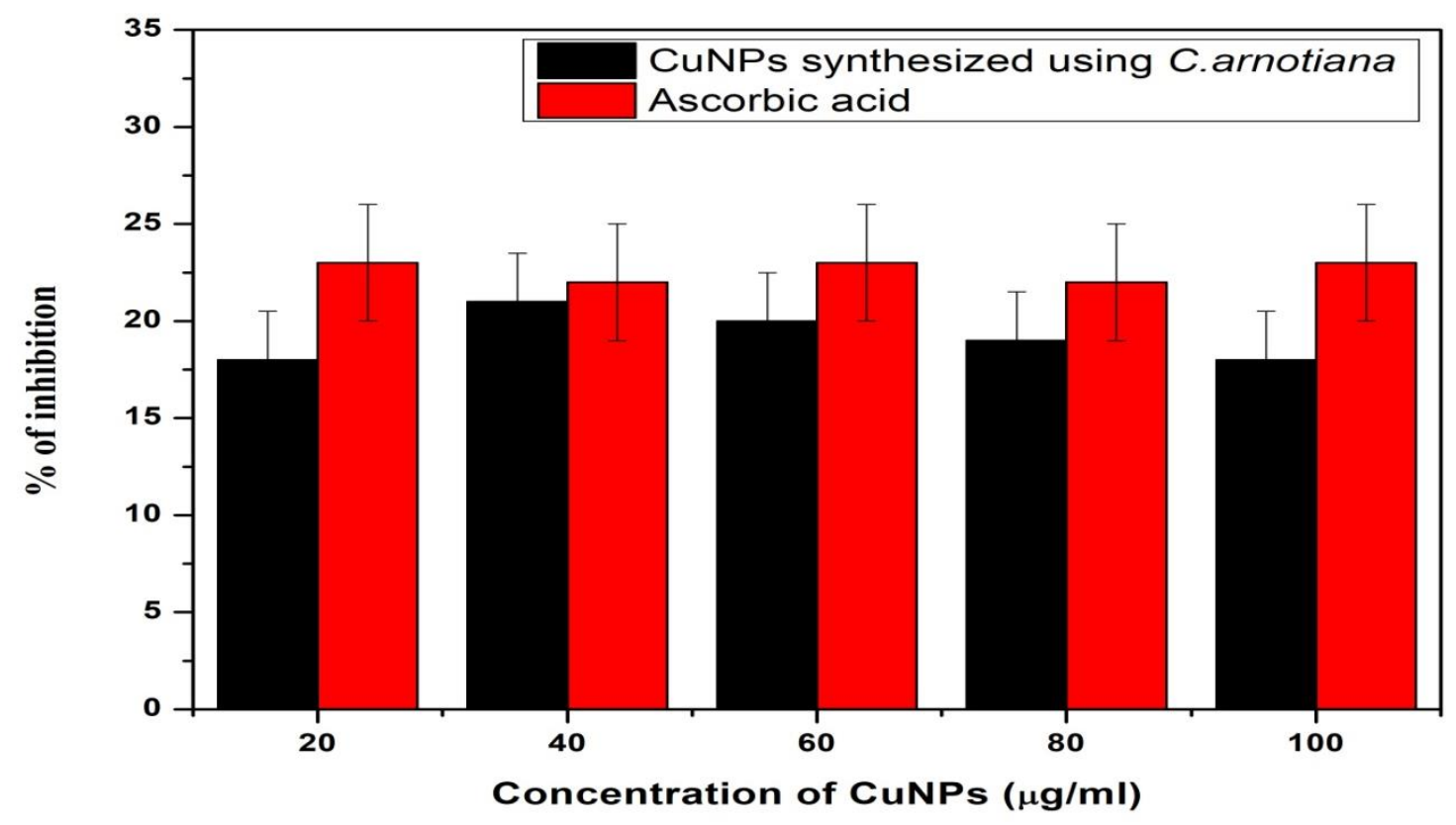

Figure 4: Antioxidant activity of CuNPs when compared with standard Ascorbic acid 


\section{Highlights}

- To prepare the copper nanoparticles using novel medicinal plant Cissus arnotiana

- Characterization of CuNPs by different microscopic techniques

- To evaluate the antioxidant and antibacterial activity 